\title{
Dynamics of outbreak and control of salmon lice on two salmon farms in the Broughton Archipelago, British Columbia
}

\author{
Martin Krkošek ${ }^{1,4, *}$, Andrew Bateman ${ }^{2}$, Stan Proboszcz ${ }^{3}$, Craig Orr ${ }^{3}$ \\ ${ }^{1}$ School of Aquatic and Fishery Science, University of Washington, Seattle, Washington 98105, USA \\ ${ }^{2}$ Department of Zoology, University of Cambridge, Cambridge CB2 3EJ, UK \\ ${ }^{3}$ Watershed Watch Salmon Society, Coquitlam, British Columbia V3K 3B7, Canada \\ ${ }^{4}$ Present address: Department of Zoology, University of Otago, Dunedin 9016, New Zealand
}

\begin{abstract}
Outbreaks of parasitic salmon lice Lepeoptheirus salmonis in sea-cage salmon farming regions of coastal seas have challenged the productivity of salmon farming industries and the conservation of wild salmon. We used a simple mathematical model to evaluate the population ecology of louse outbreaks, parasiticide treatment, and louse population decline for 2 farms in the Broughton Archipelago region of British Columbia, Canada. Results suggest that exponential population growth of lice within a farm, rather than sustained louse immigration from wild sources, drive outbreaks on farms. Model analysis indicates that louse infection pressure from farms to wild juvenile salmon may be minimized by parasiticide application 2 to 3 mo preceding the juvenile salmon outmigration. The observed timing of parasiticide use and population decline of lice on farms is consistent with reported declines of lice on wild juvenile salmon. If parasiticides do not have adverse environmental effects and lice do not evolve resistance, optimized parasiticide use on salmon farms may help reduce the spread of lice to wild salmon populations.
\end{abstract}

KEY WORDS: Salmon $\cdot$ Sea lice $\cdot$ Aquaculture $\cdot$ Parasite $\cdot$ Outbreak $\cdot$ Eradication

\section{INTRODUCTION}

The rapid growth of sea-cage salmon aquaculture in coastal seas has triggered the emergence of infestations of parasitic copepods that challenge aquaculture productivity (Johnson et al. 2004, Costello 2009a) and the conservation of wild salmon (Krkošek et al. 2007a, Costello 2009b). The salmon louse Lepeophtheirus salmonis is the focal parasite for epidemiology on salmon farms (Revie et al. 2002a,b) and population dynamics of wild salmon (Krkošek et al. 2006, Skilbrei $\&$ Wennevik 2006). Salmon lice are native to the oceans of the northern hemisphere and feed on host surface tissue, causing morbidity and mortality at high infection intensity (Pike \& Wadsworth 2000, Costello 2006). The population dynamics of sea lice and Pacific salmon Oncorhynchus spp. in connected wild-farmed fish systems may be mediated by density-dependent trans- mission (Krkošek 2010a), physiology of host defenses (Jones et al. 2006), fish size (Jones \& Hargreaves 2009), exposure period (Krkošek et al. 2009), sublethal effects on host behaviour (Webster et al. 2007, Krkošek et al. 2010), migrations of wild adult salmon (Beamish et al. 2007, Krkošek et al. 2007b), as well as abiotic and management factors (Costello 2006, Krkošek 2010b).

In British Columbia, Canada, much attention has been focused on the transmission dynamics of lice from farmed to wild juvenile salmon, and subsequent effects on wild salmon populations, since outbreaks were first reported in 2001 (Krkošek 2010b). While there has been debate on the magnitude of impact of transmission from farmed salmon on wild salmon (Krkošek et al. 2006, 2008, Riddell et al. 2008, Jones \& Hargreaves 2009), the association between salmon farms and infestations of wild juvenile Pacific salmon (Morton et al. 2004, 2008, Krkošek et al. 2005, 2006) calls for a pre- 
cautionary approach to salmon louse management on salmon farms (Krkošek 2010b). However, whereas louse dynamics on European salmon farms have been well studied (Heuch et al. 2003, Revie et al. 2003, 2005), there is comparatively little research on louse population dynamics for farms in British Columbia (Saksida et al. 2007a,b).

Thus, it is fundamental to salmon farm management and wild salmon conservation in British Columbia to understand the population dynamics of louse outbreaks and control on farmed salmon. Because lice have obligate free-swimming nauplii and copepodite stages in their lifecycle, transmission can easily occur between wild and farmed fish (Krkošek 2010b). Uncertainties include how transmission of lice from wild salmon to farmed salmon affect louse dynamics on farms (Beamish et al. 2005) as well as the response of louse population dynamics on farms to the application of chemical parasiticides, typically emamectin benzoate (Saksida et al. 2007a,b). It is of interest to determine if outbreaks are driven by population growth of lice within a farm after an initial infection, or if outbreaks result from continuous louse immigration from outside a farm. In addition, once parasiticide treatment is applied, it is of interest to know the rate of louse population decline and the time required to reach a target reduction of lice on farms. Such insights would improve knowledge of sea lice population ecology on farms and inform management to optimize management of farms in relation to wild juvenile salmon migrations.

Since infestations of wild juvenile pink Oncorhynchus gorbuscha and chum O. keta salmon were first reported in 2001 in the Broughton Archipelago, British Columbia (Morton \& Williams 2003), studies have focused extensively on juvenile pink and chum salmon as they migrate past a collection of salmon farms located on wild salmon migration routes (see Fig. 1). Heavy infestations continued in 2002 (Morton et al. 2004), 2004 and 2005 (Krkošek et al. 2006), but a one-time fallow intervention by Provincial regulators and industry reduced louse abundance in 2003 (Morton et al. 2005). Where farm data are available, studies indicate that infestations of wild juvenile salmon occurred when abundance of salmon lice on farmed salmon reached 1 to 2 gravid lice per fish and chemical treatment occurred late in the migration period (Orr 2007), which occurs between March and June. Since then, louse abundances on wild juvenile salmon have declined markedly (Jones \& Hargreaves 2007, 2009), but these changes have not been compared to abundances of lice on farmed salmon or any changes in management.

In the present paper, we develop simple theoretical models for sea lice population dynamics on farms and apply the models to data from 2 farms on the primary wild juvenile salmon migration corridor in the Broughton
Archipelago during a period of louse outbreak, parasiticide use, and louse population decline in winter 2006. The 2 farms, known as Sargeaunt Pass and Humphrey Rock (see Fig. 1), were estimated to be key drivers of infestations of wild juvenile salmon in 2004 (Krkošek et al. 2006, Orr 2007). By fitting simple models to the data on louse outbreaks and then louse population decline following parasiticide use, we are able to develop a quantitative framework for understanding the population ecology of outbreaks and the applied ecology of parasite control on these farms. The model results provide insight into the optimal timing of parasite control relative to juvenile salmon outmigrations as well as relating them to changes in louse abundance on farms and associated management changes.

\section{METHODS}

Data. The focal area for this study is the Knight Inlet - Tribune Channel corridor in the Broughton Archipelago (Fig. 1). Sea lice monitoring data were obtained from Marine Harvest Canada for 2 salmon farms at Sargeaunt Pass and Humphrey Rock locations in 2006 (Fig. 1). The fish in these farms had been stocked $\sim 1$ yr earlier. The third farm at the confluence of Tribune Channel and Knight Inlet, known as Doctor Islet, was fallow during winter and spring 2006. The farm located in northern Tribune Channel, known as Glacier Falls, was active in winter 2006 but fallow during the spring outmigration season (March to June).

Farm monitoring consisted of counting sea lice on 80 (Sargeaunt Pass) or 60 (Humphrey Rock) fish on one day at frequencies of 1 to $3 \mathrm{wk}$ over the course of the dataset. For each sampling event, 20 fish from a standard pen plus 2 to 3 random pens were sampled, giving a total of 60 fish per sampling event. Fish were caught using a box seine by luring fish into it with feed. Once collected into the box seine, the fish were dip netted out into a tote filled with seawater and tricaine methanesulfonate fish anesthetic. When the sampling was completed, the fish were released back into the net pens. Data from the Sargeaunt Pass farm went from November 5, 2005 to June 29, 2006. Data from the Humphrey Rock farm went from November 8, 2005 to June 29, 2006.

Sea lice enumeration occurred in a white counting tote while fish were anesthetized. Farm staff counted chalimus stages of lice as well as motile Lepeoptheirus salmonis and motile Caligus clemensi, a second species of louse that infects salmonids in British Columbia. The motile L. salmonis were further separated into preadult, adult male, and adult female stages. For analysis, we aggregated the motile stages of $L$. salmonis to avoid numerous cases of zero-counts which occurred at the finer resolution of pre-adult and adult male and 


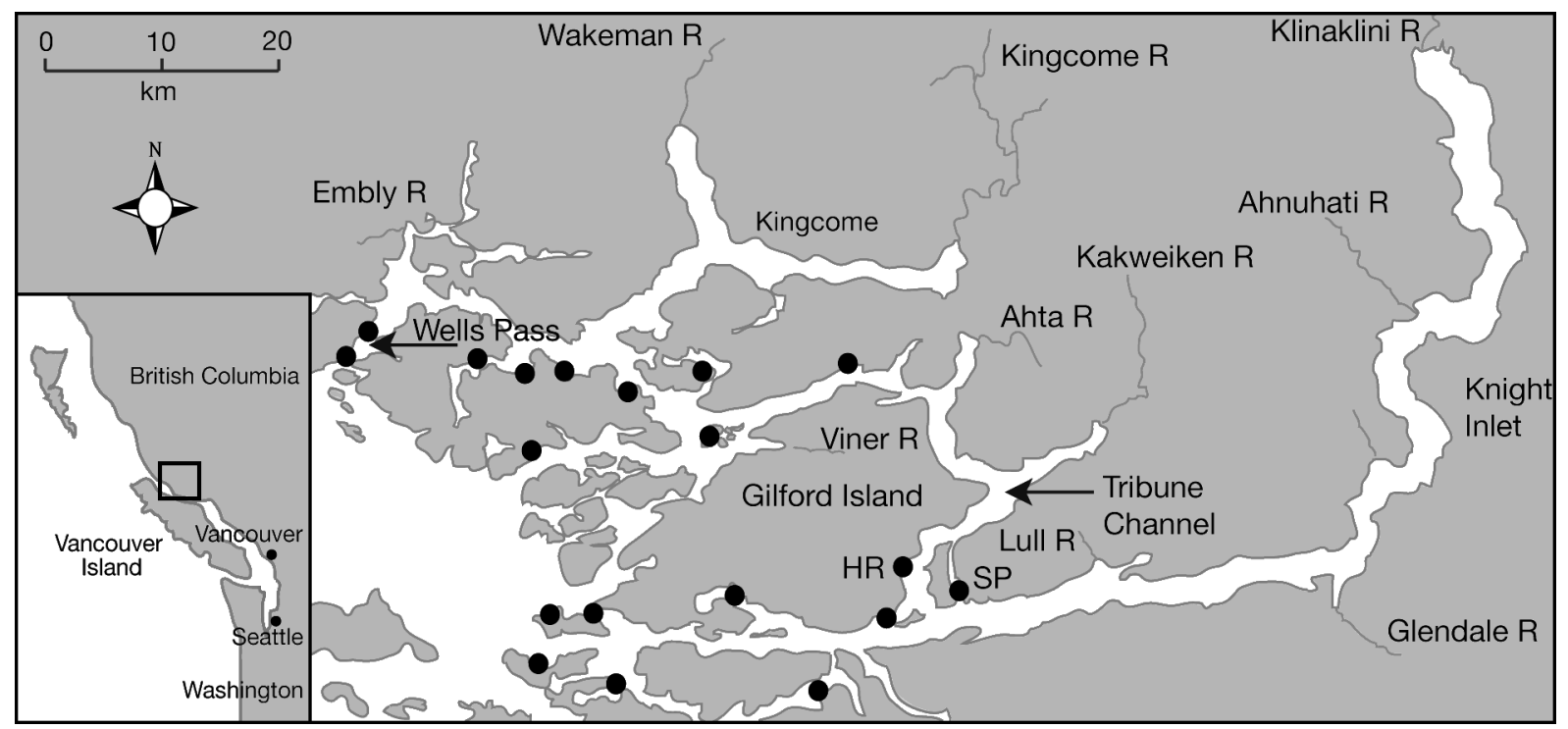

Fig. 1. Location of the 2 salmon farms, Sargeaunt Pass (SP) and Humphrey Rock (HR), within the group of farms (•) in the Broughton Archipelago, British Columbia, Canada

female stages. Parasiticides were applied to all pens on the Humphrey Rock farm commencing on February 13, whereas for the Sargeaunt Pass farm, treatment occurred for some pens on February 24 with a followup treatment on March 7 in the remaining pens.

Model. We considered 2 ecological scenarios for outbreaks of salmon lice on salmon farms. In one scenario, the outbreaks were externally driven by sources of infection outside the salmon farms. Externally driven outbreaks arise through an immigration and death process, in which copepodites enter the farm from the external environment, infect farmed fish, and complete their lifecycle. This scenario assumes that the vast majority of nauplii and copepodites produced by lice on farmed fish are dispersed into the surrounding marine environment so there is no re-infection of farmed fish. In the second scenario, outbreaks are driven by parasite population growth inside the salmon farms. The second scenario assumes an initially small population of lice colonizing the farm from the outside environment and subsequently undergoing population growth through retention of nauplii and copepodites inside the farm environment, leading to re-infection dynamics of farmed fish. Both models are simple examples of basic host-macroparasite models (Anderson \& May 1991).

The model for externally driven outbreaks is

$$
\frac{\mathrm{d} \bar{P}}{\mathrm{~d} t}=\beta L_{\mathrm{e}}-\mu \bar{P}
$$

where $\bar{P}$ is the average number of motile Lepeoptheirus salmonis per farmed fish, $t$ is time (d), $L_{\mathrm{e}}$ is the abundance (or density) of copepodites entering the farm from the external environment, $\beta$ is the transmission coefficient (the rate at which copepodites attach to a farmed fish) but modified by the proportion of attached copepodites that survive to reach motile stages, and $\mu$ is the mortality rate of motile stage $L$. salmonis. This model has a mathematical solution

$$
\bar{P}(t)=\bar{P}^{*}\left(1-\mathrm{e}^{-\mu t}\right)
$$

where $\bar{P}^{*}=\beta L_{\mathrm{e}} \times \mu^{-1}$ is the equilibrium abundance of lice that is eventually reached due to the immigration and death process. For this model the influx of lice from outside a farm, $L_{\mathrm{e}}$, is a constant parameter and is not coupled to the dynamics of lice on the farm.

The model for internally driven outbreaks couples copepodite and motile louse population dynamics in the farm, giving

$$
\begin{aligned}
& \frac{\mathrm{d} \bar{P}}{\mathrm{~d} t}=\beta L_{\mathrm{i}}-\mu \bar{P} \\
& \frac{\mathrm{d} L_{\mathrm{i}}}{\mathrm{d} t}=\lambda \bar{P} H-\beta L_{\mathrm{i}}-v L_{\mathrm{i}}
\end{aligned}
$$

Eq. (3) allows for retention of copepodites, $L_{i}$, in the farm that are produced by motile lice at rate $\lambda$ and then subsequently attach to farmed fish at rate $\beta$ or die at rate $v$. For this model, the fecundity of motile lice, $\lambda$, is the average number of copepodites produced per motile louse multiplied by the fraction that remain in the farmed environment. The number of farmed salmon in the farm is $H$. Further, Eq. (3) assumes that copepodites in the farmed environment arise from motile lice within the same farm, and that immigration of lice from outside the farm is negligible except for a small initial influx that initiates the farm population. 
Eq. (3) leads to exponential population growth of the motile louse population on a farm (May \& Anderson 1991). We make a quasi-steady state approximation by noting that the motile stage of lice is long-lived relative to the short lifespan of copepodites. This implies that the copepodite population will quickly reach an equilibrium that tracks the motile population. Setting $\frac{\mathrm{d} L_{\mathrm{i}}}{\mathrm{d} t}=0$ and solving for $L_{\mathrm{i}}$ gives $L_{\mathrm{i}}=\frac{\lambda \bar{P} H}{\beta+v}$, which simplifies Eq. (3) to

$$
\frac{\mathrm{d} \bar{P}}{\mathrm{~d} t}=\left(\frac{\beta \lambda H}{\beta+v}-\mu\right) \bar{P}
$$

The combination of parameters in Eq. (3) can be expressed as a single parameter, $r=\beta \lambda H(\beta+v)^{-1}-\mu$, and therefore Eq. (3) is simply a model for exponential growth of motile lice on a salmon farm. The solution for Eq. (3) is

$$
\bar{P}(t)=\bar{P}_{0} \mathrm{e}^{r t}
$$

where $\bar{P}_{0}$ is the initial abundance of lice per fish.

To model louse population dynamics following treatment with a parasiticide, we assume that no copepodites survive to become motiles and therefore set $\beta=0$. We also assume that motile lice die at rate $\phi$, which may be different than $\mu$. This leads to a model of exponential decline in louse populations following treatment on salmon farms, given by

$$
\frac{\mathrm{d} \bar{P}}{\mathrm{~d} t}=-\phi \bar{P}
$$

which has the solution

$$
\bar{P}(t)=\bar{P}_{T} \mathrm{e}^{-\phi(t-T)}
$$

where $\bar{P}_{T}$ is the average number of motile lice per fish at the time of treatment, which occurs at time $t=T$.

The above models assume that the environmental conditions in and around the farms are constant. In particular, the models do not accommodate seasonal or finerscale temporal variation in abiotic factors such as temperature and salinity, nor do they accommodate temporal variation in the abundance of natural hosts in the environment. As such, the analysis represents a test of whether the simplest possible theoretical models for parasite population dynamics can capture the patterns of population growth and decline of sea lice on salmon farms, and provide a starting point from which seasonal variation can be incorporated into simple mechanistic models for sea lice population dynamics on farms.

Statistical analysis. We first analyzed the outbreak portion of the data (i.e. the data preceding the application of parasiticide) by fitting and comparing 2 models, Eqs. (1) \& (3). To fit the models, we used the statistical programming language R (www.r-project.org) to encode the solutions to the corresponding models (Eqs. $2 \& 5$, respectively). Each model had 2 free parameters to be estimated: $\bar{P}^{*}$ and $\mu$ for the externally driven outbreak model; and $\bar{P}_{0}$ and $r$ for the internally driven outbreak. The models were fit according to the principles of maximum likelihood, by assuming Poisson-distributed error and using the optimization package optim in R to find the maximum likelihood parameter estimates. Though parasites tend to be aggregated on the host population, leading to negative binomial distributions (Shaw \& Dobson 1995, Shaw et al. 1998), we still used the Poisson distribution because louse abundances were generally low on the farmed fish and at low mean abundance, the negative binomial and Poisson distributions converge (McCullagh \& Nelder 1999). To compare the models, we compared their negative log likelihood values. Use of Akaike Information Criteria was unnecessary because the 2 models had the same number of parameters. Thus, the difference in negative log likelihoods is equal to the likelihood ratios of the 2 models.

Once the best model was selected for sea lice outbreaks on farms, we analyzed the full dataset for each farm including pre-treatment and post-treatment data by combining outbreak and control models as follows. The model for externally-driven dynamics was

$$
\bar{P}(t)= \begin{cases}\bar{P}^{*}\left(1-\mathrm{e}^{-\mu t}\right) & , \text { if } t<T \\ \bar{P}_{T} \mathrm{e}^{-\phi(t-T)} & , \text { if } t \geq T\end{cases}
$$

where we impose that $\bar{P}_{T}=\bar{P}^{*}\left(1-\mathrm{e}^{-\mu T}\right)$, so that the model solution is continuous. The model for internallydriven dynamics was

$$
\bar{P}(t)= \begin{cases}\bar{P}_{0} \mathrm{e}^{r t} & , \text { if } t<T \\ \bar{P}_{T} \mathrm{e}^{-\phi(t-T)} & , \text { if } t \geq T\end{cases}
$$

where we impose that $\bar{P}_{T}=\bar{P}_{0} \mathrm{e}^{r t}$, so that the model solution is continuous. To fit the model we assumed the data followed a negative binomial distribution, similar to other studies (Revie et al. 2005), and used the optimization package optim in R to find the maximum likelihood estimates as well and the $95 \%$ confidence intervals (CI) on the model parameters by extracting the Hessian matrix and corresponding standard errors. The parameters estimated in the optimization process were $\mu, \phi, \bar{P}_{T}$, and $k$ for both the model with externally driven dynamics (Eq. 8) and the model with internally driven dynamics (Eq. 9), where $k$ is the dispersion parameter in the negative binomial distribution. We applied this analysis separately to each farm and we also applied the analysis to data from both farms simultaneously by allowing $\bar{P}_{T}$ to be a farm-specific parameter and the other parameters to take the same value for both farms. Finally, with the parameter estimates from the best-supported model, we evaluate the expected time that is required post-treatment to achieve a parasite reduction target, such as a $95 \%$ reduction in parasite load. 


\section{RESULTS}

The 2 models for salmon lice outbreaks on farmed salmon produce qualitatively different dynamics (Fig. 2). Externally driven dynamics (Eq. 1) are governed by an immigration and death process that rises quickly and then reaches a stable equilibrium where the rate of copepodites entering the farm and attaching to fish is balanced by the natural mortality of lice on farmed fish. In contrast, the model for internally driven dynamics exhibits exponential growth and there is no equilibrium that is reached that can constrain parasite population growth. An important qualitative feature is that, for externally driven dynamics, parasite population growth occurs in a concave-down fashion whereas for internally driven dynamics, parasite population growth occurs in a concave-up fashion.

The pattern of salmon louse outbreak on each farm observed in the empirical data shows a conspicuous concave-up feature before treatment, indicating that, qualitatively, the model for internally driven dynamics better captures the dynamics. Comparison of the 2 models for outbreaks indicates that the model for internally driven dynamics had stronger support from the data. For the Sargeaunt Pass farm, the difference in negative log likelihoods for Eq. (5) minus Eq. (2) (which is equal to the likelihood ratio) was 144.9. For the Humphrey Rock farm, the difference in negative log likelihoods was 26.3 in favor of Eq. (5).

Given the above results, we proceeded with Eq. (9) for internally driven dynamics to analyze both the pretreatment and post-treatment data for each farm separately and for both farms. The maximum likelihood fit

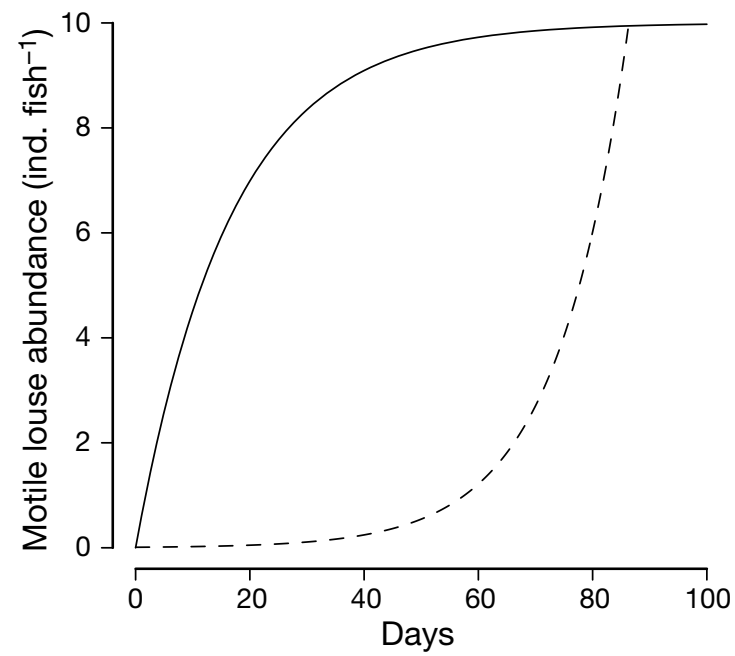

Fig. 2. Model simulations. Comparison of solutions for externally driven outbreak dynamics (Eq 1; solid line) and internally driven outbreak dynamics (Eq. 3; dashed line). Abundance is the average number of parasites per fish. Parameter values: $\beta L=0.6, \mu=0.06, r=0.08$, and $\bar{P}_{0}=0.01$. See 'Methods: Models' for definition of parameters

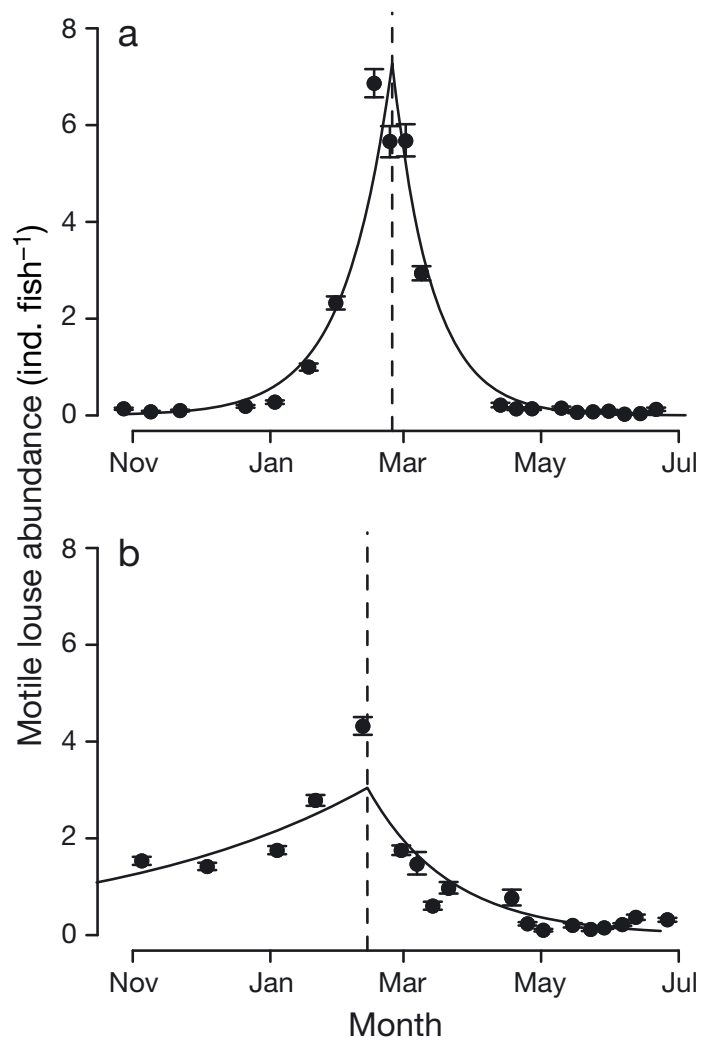

Fig. 3. Lepeoptheirus salmonis. Abundances (average no. of parasites per fish $\pm 95 \%$ bootstrapped confidence intervals) of motile salmon lice on (a) Sargeaunt Pass and (b) Humphrey Rock farms in the Broughton Archipelago in winter 20052006. Solid lines: maximum likelihood fits of the internally driven dynamics model (Eqs. 3 \& 9) when fit to the dataset for each farm separately. Vertical dotted lines: commencement of treatment with parasiticide

of the model was in good qualitative agreement with the data (Fig. 3), and there was a small range in parameter uncertainty as shown by the $95 \%$ CI on the parameter estimates (Table 1). Comparison of Eq. (9), when fit to the data from the 2 farms separately versus when fit to the 2 datasets together, with separate $\bar{P}_{T}$

Table 1. Parameter estimates and 95\% confidence intervals (CI) for the model for internally driven dynamics (Eq. 9) when fit to data from each farm separately. $r$ : rate of population growth preceding treatment with parasiticide; $\phi$ : population decline following treatment, $\bar{P}_{T}$ : average number of motile lice per fish at the time of treatment

\begin{tabular}{|lccc|}
\hline Salmon farm & $r$ & $\phi$ & $\bar{P}_{T}$ \\
\hline Sargeaunt Pass & & & \\
Estimate & 0.048 & 0.057 & 7.276 \\
CI & $0.045,0.051$ & $0.054,0.060$ & $6.882,7.669$ \\
Humphrey Rock & & & \\
Estimate & 0.009 & 0.027 & 3.044 \\
CI & $0.006,0.011$ & $0.025,0.030$ & $2.764,3.325$ \\
\hline
\end{tabular}


values gave an Akaike difference of 319.3, which is in favor of the modeling approach of treating each farm separately. The rate of population growth preceding treatment $(r)$ and population decline following treatment $(\phi)$, were both significantly different between the 2 farms, based on the parameter estimates and CI (Table 1).

The components of the models for population decline following chemical treatment on farms were converted to exponential probability distributions for louse population decline. Defining $t$ as the time since treatment, the probability of a louse being alive at time $t$ is

$$
Q(t)=\mathrm{e}^{-\phi t}
$$

and the probability that a louse is dead at a given time $t$ is therefore $F=1-Q(t)$. From here, one can calculate the time required to kill a certain fraction of the louse population, $k$, as

$$
t_{k}=-\frac{1}{\phi} \ln (1-k)
$$

Based on the estimated values of $\phi$ from the model fits to the farms (Table 1), the time to kill $95 \%$ of the parasite population was $52.6 \mathrm{~d}(95 \% \mathrm{CI}: 49.9,55.6)$ on the Sargeaunt Pass farm and $111.0 \mathrm{~d}(99.9,119.8)$ on
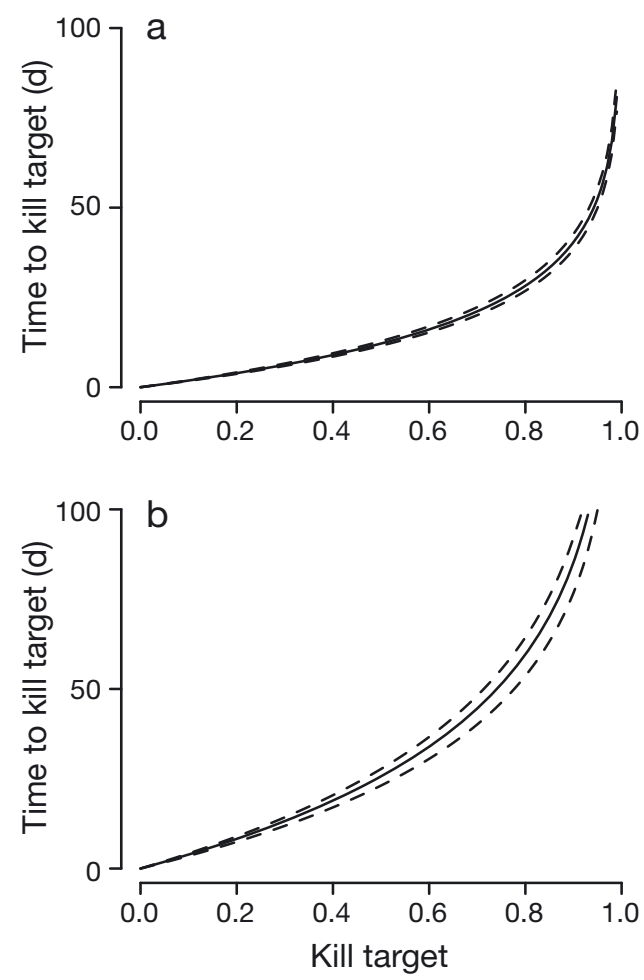

Fig. 4. Predicted time, calculated using Eq. (11), that is required to reach a kill target (fraction of salmon louse population killed) following a parasiticide application on (a) Sargeaunt Pass and (b) Humphrey Rock farms. Solid line: predicted time; dashed lines: 95\% confidence intervals as estimated for $\phi$, i.e. rate of population decline following treatment the Humphrey Rock farm. As the kill target for the louse population increases, the time required to reach the target increases non-linearly and reaches infinity as $k$ approaches $100 \%$ (Fig. 4).

\section{DISCUSSION}

Outbreaks of salmon lice in salmon farming regions of British Columbia may be linked to biotic, abiotic, and management factors (Krkošek 2010b). Biotic factors that may influence population dynamics of lice on farms are the presence of wild reservoir hosts - wild salmon-from which infection of farmed salmon must ultimately originate. The return migration of wild adult salmon to coastal waters likely transports lice from offshore reservoir populations to coastal juvenile salmon populations and farmed salmon (Beamish et al. 2007, Krkošek et al. 2007b). Local coastal populations of subadult coho Oncorhynchus kisutch and Chinook $O$. tshawytscha salmon may provide overwintering hosts for salmon lice (Beamish et al. 2007) as may farmed salmon (Krkošek 2010b). During winter, then, outbreaks of lice on salmon farms could be driven by an initial influx of lice from large populations of returning wild adult salmon followed by population growth on farms, or alternatively, could be driven by continuous immigration of lice from overwintering natural host populations. Our results indicate that the outbreaks of lice on 2 salmon farms during winter 2005-2006 were likely driven by exponential growth of the parasite population within the farms.

The models for parasite outbreaks differed qualitatively in the patterns of louse population growth between externally driven dynamics as opposed to internally driven dynamics. Externally driven dynamics follow a population growth curve that is concavedown, with louse populations eventually reaching an equilibrium. In contrast, internally driven outbreak dynamics follow exponential population growth curves that are concave-up, consistent with louse monitoring data on the farms. This does not mean, however, that louse populations on the farms are disconnected from the surrounding environment. Indeed, the spatial spread of lice from farms in the study area can extend for $30 \mathrm{~km}$ (Krkošek et al. 2005, 2006), suggesting that the population dynamics of lice on the 2 farms may be partly connected, as has been shown in Scotland (McKibben \& Hay 2004). Further, the outbreaks occurred during the same time period, indicating that they may not be independent, and that natural overwintering populations may also be affected. To evaluate the connectivity of louse outbreaks among farms, data are needed from a larger collection of farms to assess the synchrony in louse dynamics. However, any 
such synchrony could be driven by other events such as co-ordinated treatment with parasiticides or a collective rise in external infection pressure arising from the return migration of adult wild salmon.

Our conclusions regarding the internal versus external driving forces of outbreaks on farms are not merely an artifact of the dichotomous nature of the models we compared. Indeed, an intermediate model, where louse population dynamics are described by both an immigration and death process as well as internal reinfection dynamics leads to similar outcomes-either a concave-down population growth curve that reaches an endemic equilibrium if re-infection dynamics in a farm are weak or exponential population growth if reinfection dynamics in a farm are strong (Frazer et al. unpubl.). Our results indicate that sufficient progeny of lice on farmed fish are retained in the farm environment to lead to re-infection of farmed fish and exponential growth of louse populations. This suggests that farms can be a source of lice in the local marine environment, where wild salmon migrate, as would be expected because farmed salmon greatly outnumber wild salmon, particularly during winter months (Orr 2007, Dill et al. 2008, Krkošek 2010b). Thus, the exposure of wild juvenile salmon to lice during spring, and the productivity of local wild salmon populations, is likely dependent on the dynamics of outbreaks and control of louse populations on farms.

The model did not incorporate seasonal (or finerscale) temporal variation in abiotic or biotic factors. However, such factors as temperature, salinity, and abundance of wild hosts are known to vary seasonally (Krkošek 2010b). Temperature and salinity likely influence the developmental and survival rates of lice, based on laboratory studies (Johnson \& Albright 1991, Bricknell et al. 2006). The abundance of wild salmon during summer and autumn spawning migrations likely represent a change to infection pressure felt by farmed populations (Beamish et al. 2005). Such seasonal variation in these factors could be an important extension to the modeling approach we have developed here. However, in order to implement such an approach, a large dataset is needed with replication of time series of salmon lice abundance on farms in which treatment dates are distributed throughout the year such that effects of treatment can be robustly separated from environmental variation.

It is unlikely that seasonal variation confounded our analysis of louse population growth and decline. First, the cycle of population growth and decline occurred after the return migration of wild adult salmon to the region. Second, sea temperatures would be steady or declining during winter months when louse populations grew exponentially. Finally, salinity would be near full saline conditions during both the growth and decline cycle of lice on the farms, except for the end of the datasets in May through June, when snowpack melt causes a freshwater plume in the regions, which reduces sea surface salinities. Possibly, these salinity declines may contribute to the suppression of louse populations during May through June, several months after treatment with parasiticides. However, although these seasonal variations in temperature, salinity, and host abundance were unlikely to confound our results, they may very well improve the fit of the model to similar datasets when sufficient replication of time series are available. Such work may also provide field-based estimates of the sensitivity of louse demographic rates to abiotic variation.

The 2 salmon farms we studied are in critical wild juvenile salmon habitats where wild juveniles rear and migrate from natal rivers in Knight Inlet out to sea. Previous salmon lice infestations of wild juvenile pink and chum salmon in the Broughton Archipelago are linked to transmission from these 2 farms (Krkošek et al. 2006). It is therefore of great conservation interest to determine the optimal timing for the application of parasiticides on farms to minimize transmission to wild juvenile salmon during their migration past the farms. Our model provided an excellent fit to the data posttreatment, indicating exponential decline of louse populations on farms following treatment of farmed fish with emamectin benzoate. Analysis of the parameterized model indicates that it takes approximately 1.5 to 3 mo to reach a $95 \%$ reduction in farm lice populations following treatment, depending on the farm. It is unclear why there was a faster rate of parasite population decline following treatment on the Sargeaunt Pass farm than the Humphrey Rock farm. A larger dataset of multiple farms over broader timescales is needed to identify the factors underlying variation in treatment efficacy. Similar effects of delousing salmon farms following emamectin benzoate treatment have been observed for salmon farms in Maine, USA (Gustafson et al. 2006), Scotland, UK (Stone et al. 2000) and Norway (Ramstad et al. 2002), where the time to maximum efficacy has typically been on the order of $3 \mathrm{wk}$ to 1 mo.

During previous epizootics of lice on wild juvenile pink and chum salmon that occurred in Tribune Channel in 2004 (Krkošek et al. 2006), louse abundances on these farms reached 1 to 2 gravid lice per farmed fish in May when treatment was ultimately applied (Orr 2007). This amounted to a high infection pressure on wild juvenile salmon, high numbers of lice on wild juvenile salmon, and estimated mortality that reached 95 \% (Krkošek et al. 2006). In contrast, our study here indicates that precautionary application of parasiticides on farmed salmon during winter can reduce lice numbers on farmed fish to near-zero levels during spring, suggesting that infection pressure on wild juve- 
nile pink and chum salmon from these 2 farms was likely reduced by treatment in 2006. In the Broughton Archipelago, the abundance of lice on wild juvenile salmon was markedly reduced in 2006 (Jones \& Hargreaves 2009) relative to 2004 (Jones \& Hargreaves 2007), indicating treatment on farms may extend to reductions of lice in the surrounding environment. These findings are consistent with reductions in naupliar and copepodid stages of lice in plankton samples near salmon farms following treatment in Scotland (Penston et al. 2008) and British Columbia (Morton et al. 2010). Given the 1 to 3 mo timescale of delousing salmon farms we have estimated and the beginning of the juvenile salmon outmigration in this area in March (M. Krkošek pers. obs.), the optimal timing of treatment would be in January to minimize louse exposure of wild juvenile salmon.

Previous mathematical models for louse population dynamics on farmed salmon have used a detailed lifecyle model to characterize the developmental progression of lice and heavy-side functions to model the effects of treatment (Revie et al. 2005). While this may capture the patterns of louse population growth and decline on farms, it may also yield computational challenges in model fitting and parameter estimation due to the high dimensionality of the parameter space. Neither previous mathematical modeling approaches for louse population dynamics on farms, nor ours, explicitly accommodated the effects of temperature and salinity on parameters, which may be more the purview of statistical approaches such as general linear modeling (Revie et al. 2003). Nevertheless, temperature and salinity can influence louse demographic rates (Stien et al. 2005, Bricknell et al. 2006), and this remains a future modeling challenge. Our approach of aggregating louse abundances at the motile stage and simplifying a traditional Anderson-May hostmacroparasite model (Anderson \& May 1978) into one that yields simple exponential population growth and decline characterized the data well, and may simplify future analyses and make results more accessible to managers.

Management of lice on salmon farms in British Columbia is increasingly focused on protecting wild juvenile salmon from infection. Our results indicate that careful timing of parasiticide use on salmon farms relative to wild salmon migrations may lead to a significant reduction in sea lice on salmon farms during this critical period. Other studies indicate that this is consistent with a marked decline in louse abundances on wild juvenile salmon relative to years when treatment was applied late in the migration season and infestations developed (Krkošek et al. 2006, Jones \& Hargreaves 2007, Orr 2007, Jones \& Hargreaves 2009). While our results suggest parasiticides may assist managers in reducing lice and infection pressure on wild salmon, there are at least 2 important caveats. Copepod parasiticides may have unintended consequences for non-target crustaceans in marine ecosystems (Waddy et al. 2002) and lice may evolve resistance. Indeed, recent data imply resistance has developed in New Brunswick (Westcott et al. 2010), Norway (Horsberg 2010), and Scotland (Lees et al. 2008), suggesting that resistance of lice to parasiticides in British Columbia is a likely outcome. Thus, other management options, such as reducing farmed salmon density (Krkošek 2010a), harvesting early, moving farms off wild salmon migration routes, or switching to closed containment technology must also be considered as strategies for conserving and restoring wild Pacific salmon populations that migrate past salmon farms.

Acknowledgements. We thank Marine Harvest Canada for allowing us access to farms and for supplying farm data. Funding came from the Natural Science and Engineering Research Council of Canada, the Duncan and Betty Moore Foundation, the Canadian National Centre of Excellence Mathematics of Information Technology and Complex Systems (MITACS) program (with nonacademic participants: the Coastal Alliance for Aquaculture Reform, the David Suzuki Foundation, the National Geographic Society, Watershed Watch Salmon Society, the Canadian Sablefish Association, Finest at Sea, BC Wilderness Tourism Association and the Pacific Salmon Forum).

\section{LITERATURE CITED}

Anderson RM, May RM (1978) Regulation and stability of host-parasite population interactions. I. Regulatory processes. J Anim Ecol 47:219-247

Beamish RJ, Neville CM, Sweeting RM, Ambers N (2005) Sea lice on adult Pacific salmon in the coastal waters of central British Columbia, Canada. Fish Res 76:198-208

> Beamish RJ, Neville CM, Sweeting RM, Jones SRM and others (2007) A proposed life history strategy for the salmon louse, Lepeophtheirus salmonis in the subarctic Pacific. Aquaculture 264:428-440

Bricknell IR, Dalesman SJ, O'Shea B, Pert CC, Luntz AJM (2006) Effect of environmental salinity on sea lice Lepeophtheirus salmonis settlement success. Dis Aquat Org 71:201-212

Costello MJ (2006) Ecology of sea lice parasitic on farmed and wild fish. Trends Parasitol 22:475-483

Costello MJ (2009a) The global economic cost of sea lice to the salmonid farming industry. J Fish Dis 32:115-118

> Costello MJ (2009b) How sea lice from salmon farms may cause wild salmonid declines in Europe and North America and be a threat to fishes elsewhere. Proc R Soc Lond B Biol Sci 276:3385-3394

Dill LM, Connors B, Losos C, Mages P (2009) Comment on Beamish et al. 'A proposed life history strategy for the salmon louse, Lepeophtheirus salmonis in the subarctic Pacific'. Aquaculture 286:154-155

Gustafson L, Ellis S, Robinson T, Marenghi F, Endris R (2006) Efficacy of emamectin benzoate against sea lice infestations of Atlantic salmon, Salmo salar L.: evaluation in the 
absence of an untreated contemporary control. J Fish Dis 29:621-627

Heuch PA, Revie CW, Gettinby G (2003) A comparison of epidemiological patterns of salmon lice, Lepeophtheirus salmonis, infections on farmed Atlantic salmon, Salmo salar L., in Norway and Scotland. J Fish Dis 26:539-551

Horsberg TE (2010) Sea lice treatments: effects, side effects, and resistance development. Sea Lice 2010, 8th Int Sea Lice Conference, Victoria, BC

Johnson SC, Albright LJ (1991) Development, growth, and survival of Lepeophtheirus salmonis (Copepoda, Caligidae) under laboratory conditions. J Mar Biol Assoc UK 71: 425-436

Johnson SC, Treasurer JW, Bravo S, Nagasawa K, Kabata Z (2004) A review of the impact of parasitic copepods on marine aquaculture. Zool Stud 43:229-243

Jones SRM, Hargreaves NB (2007) The abundance and distribution of Lepeophtheirus salmonis (Copepoda: Caligidae) on pink (Oncorhynchus gorbuscha) and chum (O. keta) salmon in coastal British Columbia. J Parasitol 93: 1324-1331

Jones SRM, Hargreaves NB (2009) Infection threshold to estimate Lepeophtheirus salmonis-associated mortality among juvenile pink salmon. Dis Aquat Org 84:131-137

Jones S, Kim E, Dawe S (2006) Experimental infections with Lepeophtheirus salmonis (Kroyer) on threespine sticklebacks, Gasterosteus aculeatus L., and juvenile Pacific salmon, Oncorhynchus spp. J Fish Dis 29:489-495

Krkošek M (2010a) Host density thresholds and disease control for fisheries and aquaculture. Aquacult Environ Interact 1:21-32

Krkošek M (2010b) Sea lice and salmon in Pacific Canada: ecology and policy. Front Ecol Environ 8:201-209

Krkošek M, Lewis MA, Volpe JP (2005) Transmission dynamics of parasitic sea lice from farm to wild salmon. Proc Biol Sci 272:689-696

Krkošek M, Lewis MA, Morton A, Frazer LN, Volpe JP (2006) Epizootics of wild fish induced by farm fish. Proc Natl Acad Sci USA 103:15506-15510

Krkošek M, Ford JS, Morton A, Lele S, Myers RA, Lewis MA (2007a) Declining wild salmon populations in relation to parasites from farm salmon. Science 318:1772-1775

Krkošek M, Gottesfeld A, Proctor B, Rolston D, Carr-Harris C, Lewis MA (2007b) Effects of host migration, diversity, and aquaculture on sea lice threats to Pacific salmon populations. Proc Biol Sci 274:3141-3149

Krkošek M, Ford JS, Morton A, Lele S, Lewis MA (2008) Response to Comment on 'Declining wild salmon populations in relation to parasites from farm salmon'. Science 322:1790

Krkošek M, Morton A, Volpe JP, Lewis MA (2009) Sea lice and salmon population dynamics: effects of exposure time for migratory fish. Proc Biol Sci 276:2819-2828

Krkošek M, Connors B, Mages P, Peacock S and others (2010) Fish farms, parasites, and predators: implications for salmon population dynamics. Ecol Appl (in press)

Lees F, Baillie M, Gettinby G, Revie CW (2008) The efficacy of emamectin benzoate against infestations of Lepeophtheirus salmonis on farmed atlantic salmon (Salmo salar L.) in Scotland, 2002-2006. PLoS one:3:e1549

May RM, Anderson RM (1991) Infectious diseases of humans. Oxford University Press, Oxford

McCullagh P, Nelder JA (1999) Generalized linear models. Chapman \& Hall/CRC, Boca Raton, FL

- McKibben MA, Hay DW (2004) Distributions of planktonic sea lice larvae Lepeophtheirus salmonis in the inter-tidal zone in Loch Torridon, Western Scotland in relation to salmon farm production cycles. Aquacult Res 35:742-750

Morton AB, Williams R (2003) First report of a sea louse, Lepeophtheirus salmonis, infestation on juvenile pink salmon, Oncorhynchus gorbuscha, in nearshore habitat. Can Field Nat 117:634-641

> Morton A, Routledge R, Peet C, Ladwig A (2004) Sea lice (Lepeophtheirus salmonis) infection rates on juvenile pink (Oncorhynchus gorbuscha) and chum (Oncorhynchus keta) salmon in the nearshore marine environment of British Columbia, Canada. Can J Fish Aquat Sci 61: 147-157

> Morton A, Routledge RD, Williams R (2005) Temporal patterns of sea louse infestation on wild Pacific salmon in relation to the fallowing of Atlantic salmon farms. N Am J Fish Manag 25:811-821

Morton AM, Routledge R, Krkošek M (2008) Sea lice infestation of wild juvenile salmon and herring associated with fish farms off the east central coast of Vancouver Island, BC. N Am J Fish Manag 28:523-532

Morton A, McConnell A, Routledge R, Krkošek M (2010) Sea lice dispersion and salmon survival in relation to salmon farm activity in the Broughton Archipelago. ICES J Mar Sci doi:10.1093/icesjms/fsq146

> Orr C (2007) Estimated sea louse egg production from Marine Harvest Canada farmed Atlantic salmon in the Broughton Archipelago, British Columbia, 2003-2004. N Am J Fish Manage 27:187-197

> Penston MJ, Millar CP, Davies IM (2008) Reduced Lepeophtheirus salmonis larval abundance in a sea loch on the west coast of Scotland between 2002 and 2006. Dis Aquat Org 81:109-117

> Pike AW, Wadsworth SL (1999) Sealice on salmonids: their biology and control. Adv Parasitol 44:233-337

> Ramstad A, Colquhoun DJ, Nordmo R, Sutherland IH, Simmons R (2002) Field trials in Norway with $\operatorname{SLICE}^{\circledR}(0.2 \%$ emamectin benzoate) for the oral treatment of sea lice infestation in farmed Atlantic salmon Salmo salar. Dis Aquat Org 50:29-33

> Revie CW, Gettinby G, Treasurer JW, Grant AN, Reid SWJ (2002a) Sea lice infestations on farmed Atlantic salmon in Scotland and the use of ectoparasitic treatments. Vet Rec 151:753-757

> Revie CW, Gettinby G, Treasurer JW, Rae GH, Clark N (2002b) Temporal, environmental and management factors influencing the epidemiological patterns of sea lice ( $L e p$ eophtheirus salmonis) infestations on farmed Atlantic salmon (Salmo salar) in Scotland. Pest Manag Sci 58:576-584

> Revie CW, Gettinby G, Treasurer JW, Wallace C (2003) Identifying epidemiological factors affecting sea lice Lepeophtheirus salmonis abundance on Scottish salmon farms using general linear models. Dis Aquat Org 57:85-95

Revie CW, Robbins C, Gettinby G, Kelly L, Treasurer JW (2005) A mathematical model of the growth of sea lice, Lepeophtheirus salmonis, populations on farmed Atlantic salmon, Salmo salar L., in Scotland and its use in the assessment of treatment strategies. J Fish Dis 28:603-613

Riddell BE, Beamish RJ, Richards LR, Candy JR (2008) Comment on 'Declining wild salmon populations in relation to parasites from farm salmon'. Science 322:1790

Saksida S, Constantine J, Karreman GA, Donald A (2007a) Evaluation of sea lice abundance levels on farmed Atlantic salmon (Salmo salar L.) located in the Broughton Archipelago of British Columbia from 2003 to 2005. Aquacult Res 38:219-231

Saksida S, Karreman GA, Constantine J, Donald A (2007b) Differences in Lepeophtheirus salmonis abundance levels on Atlantic salmon farms in the Broughton Archipelago, 
British Columbia, Canada. J Fish Dis 30:357-366

Shaw DJ, Dobson AP (1995) Patterns of macroparasite abundance and aggregation in wildlife populations: a quantitative review. Parasitology 111:S111-S133

Shaw DJ, Grenfell BT, Dobson AP (1998) Patterns of macroparasite aggregation in wildlife host populations. Parasitology 117:597-610

Skilbrei OT, Wennevik V (2006) Survival and growth of searanched Atlantic salmon, Salmo salar L., treated against sea lice before release. ICES J Mar Sci 63:1317-1325

Stien A, Bjørn PA, Heuch PA, Elston DA (2005) Population dynamics of salmon lice Lepeophtheirus salmonis on Atlantic salmon and sea trout. Mar Ecol Prog Ser 290: 263-275

Stone J, Sutherland IH, Sommerville C, Richards RH, Varma KJ (2000) Field trials to evaluate the efficacy of emamectin

Editorial responsibility: Bengt Finstad,

Trondheim, Norway benzoate in the control of sea lice, Lepeophtheirus salmonis (Kroyer) and Caligus elongatus Nordmann, infestations in Atlantic salmon Salmo salar L. Aquaculture 186: 205-219

Waddy SL, Burridge LE, Hamilton MN, Mercer SM, Aiken DE, Haya K (2002) Emamectin benzoate induces molting in American lobster, Homarus americanus. Can J Fish Aquat Sci 59:1096-1099

Webster SJ, Dill LM, Butterworth K (2007) The effect of sea lice infestation on the salinity preference and energetic expenditure of juvenile pink salmon (Oncorhynchus gorbuscha). Can J Fish Aquat Sci 64:672-680

Westcott JD, Revie CW, Griffin BL, Hammell KL 2010. Evidence of sea lice Lepeophtheirus salmonis tolerance to emamectin benzoate in New Brunswick, Canada. Sea Lice 2010, 8th Int Sea Lice Conference, Victoria, BC

Submitted: June 18, 2010; Accepted: November 15, 2010 Proofs received from author(s): November 29, 2010 